\title{
LA PULSIÓN ENSAYÍSTICA EN EL CÓMIC ESPAÑOL CONTEMPORÁNEO: UNA PRIMERA APROXIMACIÓN.
}

\author{
Eduardo Hernández Cano
}

(Université Paris-Sorbonne)

Desde hace algo más de una década, el lenguaje que desde finales del siglo diecinueve se ha servido de la combinación sucesiva de imágenes y textos para pensar y narrar, que cada tradición nacional denomina de una forma específica — comic, tebeo, historieta, bande dessinée, manga, histórias em quadrinhos, fumetto - ha quedado con frecuencia atrapado bajo la denominación de «novela gráfica». Como bien ha señalado Álvaro Pons, este etiquetado ha tenido mayor éxito en ciertos países, como los Estados Unidos y España (Ruiz Giménez 2017)'. En la mayor parte de los casos, el término novela gráfica parece haber funcionado como una suerte de placebo cultural, destinado a eliminar los síntomas de insuficiencia cultural tanto de quienes consumían como de quienes producían este tipo de lenguaje, vinculándolo a la literatura de ficción entendida como paradigma del valor cultural 2 . Pese a los intentos de sofisticar la denominación de «novela gráfica» por algunos teóricos y creadores como Eddie Campbell, para quien el término «signifies a movement, or an ongoing event, rather than a form» (2004), lo cierto es que con frecuencia se unen al considerar este lenguaje una mezcla de consideraciones heterogéneas, que unas veces tienen que ver con el formato y otras con el tipo de público al que se dirige o la relación que el

\footnotetext{
${ }^{1}$ Ver Gravett (2005) y García (2010). Merece la pena comparar estos trabajos con la historia global de Dan Mazur y Alexander Danner (2014), que utiliza la denominación reconocible por el público anglosajón al que se dirige en el título mientras que en el texto mismo utiliza las diferentes denominaciones nacionales.

${ }^{2}$ Esta búsqueda de legitimación que remite a la literatura antecede, en realidad, a la extensión del uso de «novela gráfica» (Witek 1989: 3-12). Curiosamente, los intentos de remitir el valor del cómic al mundo del arte son menos 
autor mantiene con su obra (Altares 2009)3. Por último, el uso historiográfico indiscriminado del término «novela gráfica» plantea un problema fundamental para la comprensión de la evolución de este lenguaje, al no distinguir muchas historias y ensayos entre lo que sería una visión ideal construida por sus autores como relato y el deseable análisis sociohistórico de los cambios en el medio surgidos del diálogo entre un autor y la cultura desde la que trabaja (García 2010).

Esta necesidad simultánea de legitimación social del medio a través de la denominación «novela gráfica» y de construcción de una narrativa que sostenga el uso de esta, ha debilitado notablemente nuestra comprensión del cómic como soporte no sólo de distintos modos narrativos, sino también de distintas formas de aproximarse a la realidad. No necesitamos más que pensar en una obra fundamental para el desarrollo de nuestra comprensión actual del cómic como medio, Understanding Comics. The Invisible Art, de Scott McCloud (1993), que poco tiene que ver con la narrativa establecida sobre la «novela gráfica». La reflexión de McCloud sobre el cómic como medio se construye significativamente como un ensayo, elaborado a través de ese mismo lenguaje lecto-visual que analiza. La obra de McCloud es sólo el ejemplo más representativo de la importancia que los géneros de no ficción han tenido en el desarrollo del cómic contemporáneo, hasta tal punto que cabría argumentar que estos géneros —la autobiografía, el relato histórico, el reportaje, el ensayo— han tenido un papel mucho más importante que la ficción en su maduración temática.

Creo por ello que es necesario atender a la entrada y creciente importancia de los géneros de no ficción en el cómic contemporáneo, que para casos específicos como los del cómic histórico o la autobiografía conocemos muy bien, como paso previo a un intento de explorar el progresivo surgimiento en estos de una retórica y un registro de reflexión sobre la realidad que podemos vincular legítimamente con la idea de ensayo. Esta evolución puede observarse de manera particular en muchas de las obras fundamentales del cómic español de las últimas décadas, tanto de autores de la primera generación interesada en acercar el medio del cómic a un público y unos temas adultos —Carlos Giménez, Max, Miguel Gallardo—, como en los creadores más interesantes surgidos desde mediados de los noventa —Manel Fontdevila, Paco Roca, Santiago García-.

\footnotetext{
${ }^{3}$ Las consideraciones sobre la novela gráfica como formato aparecen constantemente en las intervenciones de algunos de sus más conocidos creadores en el monográfico «Comics \& Media» (Chute y Jagoda 2014). Merece la pena señalar al respecto que, contra lo que sucede en el cómic actual, el formato editorial de la novela es uno de los más estandarizados en el mundo editorial, mientras que el referente de muchos creadores en términos de formato — pienso en Chris Wareparece provenir del mundo del arte y la ilustración. Sobre la evolución del cómic dirigido a adultos ver Sabin (1993) y 


\section{Notas para una historia: el ensayo histórico y político en los cómics de la Transición} (1975-1981)

Todo intento de trazar una genealogía del ensayo en el cómic español debe partir del momento de surgimiento y dificultosa consolidación inicial de un cómic adulto en los años de la Transición`. Pero este origen lo es sólo de una tradición interrumpida, pues el modelo de cómic reflexivo, dirigido a la exploración crítica de la historia y la sociedad, que se cultivó a finales de los años setenta pronto desapareció bajo el peso de la progresiva comercialización del medio que se dio en la proliferación de revistas mensuales de cómic, sostenidas sobre la serialización de relatos de ficción casi siempre protagonizados por personajes recurrentes, que hicieron posible la profesionalización de los creadores de cómic pero limitaron claramente su capacidad de expresión.

La mayor parte de los creadores que se interesaron por el potencial para la reflexión sobre el mundo del cómic provenían no tanto de la llamada contracultura como de la floreciente cultura militante de la Transición. Por ello, practicaron un tipo de cómic que estaba entre el ensayo reflexivo y el texto de opinión política. Nadie encarna este momento de experimentación formal y crítica política como El Cubri, nombre común bajo el que se reunían el guionista Felipe Hernández Cava y los ilustradores Saturio Alonso y Pedro Arjona. Muy vinculados a las luchas populares durante los años de la Transición, su obra publicada se centró sin embargo en la crítica política internacional, con el imperialismo como foco principal de ésta (El Cubri 2008). Se dieron a conocer en 1973 con un cómic «Aventuras en el País de las Maravillas» que quedó finalista en el XI Certamen Internacional de Cine para Niños de Gijón (El Cubri 1974). Como tantas otras obras suyas de la época, «Aventuras en el País de las Maravillas» utilizaba el montaje de textos e imágenes de distintas épocas y procedencias para construir una interpretación de lo que se consideraba la lógica común —entre el racismo puro y la pura voluntad de poder—en los ataques perpetrados con armas nucleares contra civiles por parte del ejercito de los Estados Unidos durante la Segunda Guerra Mundial y sus prácticas en la entonces contemporánea guerra de Vietnam. Este y otros cómics de carácter experimental y político de sus primeros años, casi siempre centrados en la cuestión de la lucha contra el neocolonialismo, de Vietnam a Argelia, fueron recogidos en 1975 en El que parte y reparte se queda la mejor parte (El Cubri 1975a). Aquellos que se alejaban de lo puramente narrativo para tomar un carácter más ensayístico,

\footnotetext{
${ }^{4}$ Es necesario señalar que la línea que estudiamos aquí ha recibido escasa atención en las obras que hasta ahora se han ocupado de este periodo (Lladó 2001) (Dopico 2005) (Pérez del Solar 2013).
} 
como «Los entusiastas de la guerra prefieren un napalm duro, pero con filtro ¿Y usted?», que elaboraba una reflexión sobre la relación entre la sociedad de consumo y el militarismo en los Estados Unidos, utilizaban un lenguaje más cercano al del fotomontaje, con el uso referencial de imágenes recontextualizadas, que al mismo tiempo que remitía al objeto de la imagen lo recontextualizaba de un modo que ofrecía una lectura política de la misma. De este modo se reutilizaban diversos lenguajes textuales y visuales —las encuestas de opinión, la publicidad, los discursos políticos, la fotografía de guerra-, que contrastados con las representaciones de la realidad del neocolonialismo adquirían un nuevo significado.

Estas estrategias de montaje serían dominantes en el desarrollo del cómic como medio para el ensayo que El Cubri desarrolló en los años posteriores ${ }^{5}$. Significativamente, la mayor parte de estos trabajos aparecieron no en revistas de cómic, sino en distintas revistas especializadas, integrados dentro de las mismas de tal manera que, como veremos, se sugería una equivalencia en términos de capacidad para la producción de discurso entre estos cómics y los restantes artículos. Sus siguientes ensayos aparecieron a partir de otoño de 1975 en la revista de política y sociología Zona Abierta, entre los que merece la pena destacar «Una lección de biología del Dr. Römpp en 1936» (El Cubri 1975b), construido sobre una estructura dialéctica, que dividía cada página en dos horizontalmente, en cuya parte superior aparecían diversos personajes de la cultura de masas citando fragmentos del libro de antropología racista del Dr. Römpp, cuya traducción fue publicada en Barcelona en 1936, mientras que en la parte de abajo alternaban imágenes de campos de concentración, Vietnam, la Comuna, la muerte del Ché o la guerra civil española, modificadas a partir de fotografías para darles apariencia de grabados. De manera transparente, El Cubri insistía así en el que era su tema fundamental de estos años, el modo en que la violencia, en este caso bajo la forma del racismo, era inscrita y normalizada por la cultura de masas. Este, como sus restantes trabajos para Zona Abierta, aparecía con el mismo rango que los artículos de los restantes colaboradores, sumando su codificación visual de ideas a la reflexión sobre las condiciones políticas y sociales del mundo contemporáneo que caracterizaban a la revista.

La integración más perfecta con el medio impreso se dio unos años más tarde en sus colaboraciones para la revista CAU. Publicación del Colegio Oficial de Aparejadores y Arquitectos

\footnotetext{
${ }^{5} \mathrm{He}$ tratado en detalle estos cómics en la conferencia «Un nuevo medio para una nueva práctica intelectual: El Cubri y el cómic político para adultos (1973-1984)», presentada en el coloquio La España Actual: cuarenta años de historia (1976-2016). Cádiz, 10-12 de mayo de 2017.
} 
Técnicos de Barcelona, a la que llegaron en una etapa de «reflexión y crítica radical», en la que los diversos colaboradores trataban de discutir

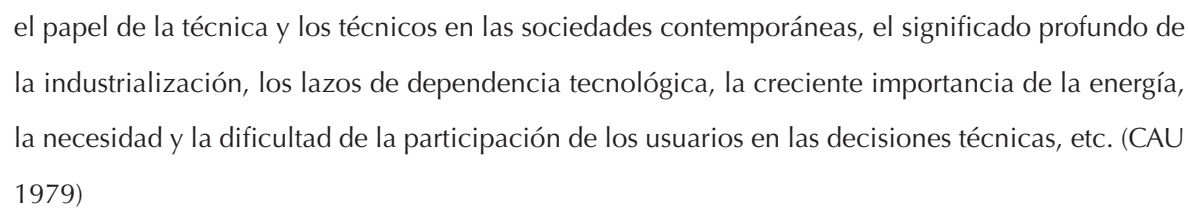

El interés de El Cubri por los problemas de habitación y del tejido urbano les había Ilevado a trabajar ya con la revista barcelonesa ;Butifarra! y con diversas asociaciones de barrio madrileñas, y ahora lo harían con un carácter más ensayístico en $C A U$, aplicándose precisamente a esos problemas relativos a la tecnología, los medios de producción y la habitación, que preocupaban en la revista en colaboraciones como «Revolución científico-técnica versus lucha de clases» (El Cubri 1977), que de nuevo presentaba un argumento dialéctico a través de dos imágenes, una cita de de La forja de Vulcano de Velázquez y un burgués decimonónico, que articulaban un diálogo en el que se contrastaba la idea de una sociedad tecnológica como condición básica del presente y un discurso, encarnado por los trabajadores de la forja, más tradicionalmente marxista, en el que el motor de la historia seguía siendo la lucha de clases y no la tecnología. Durante los años siguientes continuaron publicando cómics en los que se reflexionaba políticamente sobre la crisis del capitalismo y el conocimiento técnico (El Cubri 1978a) o sobre la apropiación de la noción misma de tecnología por el capitalismo (El Cubri 1978b), antes de dirigir sus colaboraciones hacia otro de sus registros, el del humor.

Fue precisamente en las revistas humorísticas, que conocieron un gran desarrollo y, sobre todo, un marcado carácter político durante los últimos años del franquismo y la Transición, donde aparecieron otros ejemplos de uso del cómic y la narrativa visual como medio para la reflexión sobre la realidad nacional e internacional. Se trataba con frecuencia de cómics que oscilaban entre la divulgación y el comentario político, pero que poseían siempre un marcado carácter de intervención intelectual, no necesariamente buscando el humor que se suponía a las colaboraciones del medio en el que aparecían. El ejemplo más claro de esto fue la revista EI Papus (1973-1986), en la que aparecieron a partir de la muerte de Franco las páginas dibujadas por Carlos Giménez, con frecuencia sobre guiones de Ivá, que luego serían recogidas en los tres 
primeros volúmenes de la colección Papel Vivo de Ediciones de la Torre, España Una, España Grande y España Libre (Giménez 2001). Se trataba de verdaderos cómics de opinión sobre la realidad inmediata, alternando algunos ejercicios humorísticos con reflexiones de mayor seriedad sobre la violencia política en esos años, utilizando en «Por la boca muere el pez» un montaje de declaraciones de Mariano Sánchez Covisa, fundador de los Guerrilleros de Cristo Rey, con dibujos que se referían a diversas acciones violentas (Giménez 2001: 80-81), o «Pasado imperfecto de indicativo» (Giménez 2001: 118-119), meditación sobre la sensación de logro insuficiente que la democracia recién llegada podía tener para quien había vivido guerra, exilio y dictadura. Verdaderos ensayos gráficos, el trabajo hecho por Ivá y Giménez quedaba muy lejos del tipo de humor político que practicaba no sólo El Papus, sino también la revista que lo heredaría y mantendría durante décadas, El Jueves, que ya en esos años presentaba cómics que preferían abandonar el tono reflexivo en favor de pequeñas secuencias narrativas protagonizadas por personajes satíricos recurrentes (Vilches 2004: 141-146).

Aún más lejos del humor que definía El Papus está la serie de cómics de Francisco M. Arroyo y Adolfo Usero publicada entre 1976 y 1979, recogida en 1980 para la colección Papel Vivo bajo el título de Dossiers (Arroyo y Usero 1980). Dossiers reunía una serie de historias de dos páginas en las que se seleccionaba un acontecimiento histórico contemporáneo o un tema de importancia social, de la pena de muerte al fútbol, y se ofrecía una reflexión política sobre el mismo, que lo alejaba de la mera función histórico-divulgativa para convertirse en una vía de educación política para los lectores de izquierda de El Papus.

Todavía podemos considerar parte de este momento el volumen Argelia, guionizado por Felipe Hernández Cava a partir del relato de Omar, un militante independentista argelino, e ilustrado por Luis García y Adolfo Usero (García, Usero, Omar y Hernández Cava 1979). Argelia tomaba una forma muy pura de ensayo, mucho menos experimental formalmente que los trabajos de Hernández Cava junto a El Cubri, realizando una reflexión de larga duración para tratar de comprender, desde su origen en el imperialismo decimonónico, el surgimiento de un independentismo argelino lanzado a la violencia política y a la guerra de independencia.

La década de los ochenta supondría, como hemos señalado, la casi total desaparición de este tipo de cómic de ensayo político de tintes históricos. No por ello debemos olvidar esta etapa de la Transición, marcada por preocupaciones políticas y sociales, como un precedente de 
una cierta concepción del cómic adulto que buscó aclimatar al medio cierto tipo de prácticas y temas propios del ensayismo de su época.

\section{Subjetividad y ensayo: la autobiografía como espacio de reflexión}

La evolución del cómic en España durante las décadas de los ochenta y noventa, mediatizada por el auge y caída de las revistas de cómic mensuales, estuvo dominada por los relatos narrativos seriales, que con frecuencia derivaban a un tono más juvenil que el del ideal público adulto que se había tratado de buscar en la década anterior (Altarriba 2002: 94-119) (Guiral 2011: 194-208) (Díaz de Guereñu 2011). Esta situación cambió de forma casi inmediata a partir de 2007, en que comenzó a asentarse una reconfiguración del mercado editorial centrado en obras monográficas sostenida por un nuevo público adulto. Fue a partir de entonces cuando la reflexión ensayística entró de manera definitiva en el cómic español, por unas vías muy diferentes a las de ese momento inicial que acabamos de ver.

Este giro en la concepción y el público del cómic está inseparablemente ligado a la aparición de dos cómics, Arrugas (Roca 2007), de Paco Roca, y María y yo (Gallardo 2007), de Miguel Gallardo, ambos reconocidos además institucionalmente de manera inmediata con, respectivamente, el Premio Nacional del Cómic de España y el Premio Nacional de Cómic de Cataluña concedidos el año siguiente. Ambas obras se convertirían en paradigma de un nuevo cómic social, que se alejaba del enfoque netamente político que el cómic adulto había tenido en los años setenta, ofreciendo una imagen de lo social mediada por la experiencia subjetiva, lo que resultaba en una aproximación que podríamos denominar humanística. Pero el interés de estas obras (o sus derivaciones, en el caso de Roca) para mi argumento está en la producción de unos recursos formales derivados de las convenciones del cómic autobiográfico que serán utilizados en la recuperación del enfoque ensayístico en el cómic español contemporáneo. Desde finales de los años setenta y, de manera destacada a partir de los años noventa, la biografía se ha convertido no sólo en una de las vías fundamentales para la renovación y afianzamiento del cómic adulto, desde los Estados Unidos a Francia, sino también en el espacio idóneo en el cómic contemporáneo para el surgimiento de una voz autorial cuyo punto de vista reflexivo sobre el mundo, que en los autores de más valor va mucho más allá de la mera autoobservación de la propia vida, tiene mucho que ver con la práctica ensayística (Chaney 2011) (El Refaie 2012). 
Si Arrugas se presentaba formalmente como un relato en tercera persona, a través del cual Paco Roca reflexionaba simultáneamente sobre la enfermedad —el Alzheimer-y sobre la vejez, María y yo suponía ya una aproximación a su objeto que claramente tenía que ver con los géneros de no ficción y el ensayo en particular. Gallardo compartía con Roca el tema de la enfermedad, pero en este caso vivida en primera persona, utilizando la narración autobiográfica no sólo para contar la experiencia directa del autismo en la convivencia con su hija María, sino también para, partiendo de ella, elaborar una reflexión sobre el autismo que tiene, por esa misma subjetividad, una dimensión ensayística.

El interés de Gallardo por el recurso a la presencia del autor en sus cómics aparece desde finales de los ochenta, precisamente en trabajos que tratan de constituirse, entonces todavía muy teñidos del humor que había definido su primera etapa trabajando con el personaje de Makoki, como reflexiones sobre temas concretos. Los trabajos recogidos en Toda la verdad sobre el informe "G» (Gallardo 2000), que reúne historias cortas desde comienzos de su carrera, son ejemplares en este sentido, constituyendo breves reflexiones que se acercan a la sátira cultural, como en «Lo peor es lo mejor», sobre la fascinación estética por los elementos más perecederos de la cultura de masas, o «Yo fui dibujante de comic», una meditación irónica sobre su profesión en el momento en que el cómic estaba adquiriendo una nueva importancia cultural (Gallardo 2001: 44-45 y 40-41). En ambas, el propio Gallardo se introduce como narrador dibujándose en la página, presentándose como el autor directo de las opiniones dadas en estos cómics sobre el mundo cultural que lo rodea, claramente mediado por su propia experiencia y reflexión.

Este uso de la primera persona inscrita, dibujada en el propio texto, condición necesaria de la autobiografía en el cómic, alcanzará una dimensión nueva en María y yo. Esta obra es simultáneamente un cuaderno de apuntes, un dietario, un libro de viajes y un fragmento de su propia vida, unificado todo ello por el tema común del autismo y el enfoque subjetivo de Gallardo. Constituye una reflexión sobre el autismo y la compleja experiencia de ser padre de una niña que lo sufre, llena de frustraciones, pero también de inesperados placeres cuando surge la comunicación. Gallardo no se limita a contar qué supone ser padre de una niña autista, sino que elabora todo un argumento, tanto textual como visual —el dibujo es, en definitiva, clave en su relación con María - para demostrar que, pese a la peculiar condición de la enfermedad, siempre existe la posibilidad de la comunicación, tema al que volverá en otro de sus cómics 
autobiográficos más brillantes, «Una navidad en casa» (Gallardo, 2013).

Este uso de la primera persona autobiográfica no sólo para contar una experiencia personal subjetiva, sino también para ponerse reflexivamente frente a un cierto aspecto de la realidad, se convertiría en uno de los recursos formales definitivos para la creación de un modelo de cómic-ensayo en un volumen compartido con Paco Roca, de apariencia menor, circunstancial, Emotional World Tour (Gallardo y Roca 2009), subtitulado «Diarios itinerantes». Surgido como un cuaderno de viaje de los diversos encuentros compartidos entre Gallardo y Roca durante la promoción de sus obras de 2007, Emotional World Tour sirve, sin duda, para la anécdota, pero abre también un espacio para la reflexión e incluso para la metarreflexión en sus páginas, en particular en los dos cómics con los que se abre. Partiendo de las conferencias con que cada uno de ellos comenzaba sus charlas en distintos lugares de España, Gallardo y Roca desarrollan en esta obra sendos ensayos de reflexión sobre su propio trabajo en María y yo y Arrugas, sobre su origen y su alcance. Ambos comparten además una misma gramática estructural, componiendo sus páginas sobre una trama básica de $3 \times 3$ viñetas, popularizada en los años ochenta por el guionista británico Alan Moore, que establece un claro límite para el desarrollo del dibujo, pero en el que ambos parecen reconocer un recurso idóneo para la exposición plástica de ideas.

En el caso de Gallardo (Gallardo y Roca 2009: 9-17), se sirve de esta forma para unir textos y dibujos sin una relación sintáctica entre unas viñetas y otras, ofreciendo verdaderos ejemplos de uso reflexivo de la ilustración, como cuando la incógnita de qué es lo que le sucede a la pequeña María es expresada como una pieza de un puzzle colocada sobre un dibujo de su cabeza, o cuando expresa el impacto del diagnóstico de autismo en los padres a través de un espacio laberíntico presidido por esa palabra que se teme nombrar, representada sólo por su inicial (Gallardo y Roca 2009: 11). Roca, por su parte, aun utilizando la misma matriz expositiva, tenderá más a la escena narrativa, en vez del montaje paralelo de texto y dibujo (Gallardo y Roca 2009: 21-30). Valiéndose ahora del enfoque autobiográfico, Roca presenta Arrugas de manera explícita como una reflexión sobre la vejez, mucho más que sobre el Alzheimer, exponiendo la compleja génesis de la obra a partir de la experiencia personal, de la experiencia de personas próximas a él y de la observación de la imagen de la vejez en la sociedad contemporánea. De algún modo, Roca construye un ensayo narrativo para demostrar que su narración tenía mucho de ensayo, de reflexión, pese a su forma de narrativa de ficción. La colaboración en Emotional 
World Tour propiciaría en Paco Roca, probablemente el mayor talento narrativo en el cómic español desde Carlos Giménez, la apertura al uso de la retórica autobiográfica como estrategia para la presentación de reflexiones ensayísticas (Azpitarte 2012: 201). En definitiva, pese a ser reconocido por su cuidadoso trabajo de construcción de una cierta transparencia narrativa en sus cómics, Roca es en casi todas sus obras esencialmente alguien que piensa sobre el objeto cuyo relato aborda.

Emotional World Tour sirvió también, de forma indirecta, para documentar el contexto de recepción de Arrugas y María y yo, que dio forma a las sucesivas invitaciones a sus autores, un contexto de creciente interés por un cómic serio, dirigido a un público adulto y que no se dudaba en caracterizar, pese al marcado carácter intimista de estos trabajos, como social. Se producía así una síntesis entre un modo retórico, el de la autobiografía, y un nuevo interés, tanto por parte de los autores como del público, por cómics que mostrasen una visión reflexiva de un fenómeno social, algo que tendría su pleno desarrollo en el cómic de carácter periodístico, en el que también se puede percibir la pulsión ensayística.

\section{Entre la crónica y el reportaje. La confluencia de la mirada periodística y el ensayo en el cómic}

El creciente interés por cómics que reflexionaban sobre cuestiones de relevancia social, como hemos visto, propició el salto de algunos autores, como es el caso paradigmático de Paco Roca, a la prensa periódica, en la que se les abrió un espacio diferenciado al que el cómic había ocupado hasta entonces, esencialmente dirigido al público infantil, un nuevo espacio en el que de lo que se trataba era de exponer la opinión sobre un tema específico de un creador de cómics, como antes se había hecho con periodistas, científicos y otros intelectuales.

En sus colaboraciones en prensa, Paco Roca asumirá de manera definitiva la retórica autobiográfica ensayada junto a Gallardo en Emotional World Tour, creando un protagonista que se identifica con él y que actúa como observador dotado de una voz reflexiva, como un verdadero autor que enuncia reflexiones sobre el mundo a partir de su experiencia de observarlo. Paco Roca creó así su «hombre en pijama», inicialmente para el periódico valenciano Las Provincias, donde publicó entre marzo de 2010 y julio de 2011 sus Memorias de un Hombre en Pijama, trasladado después como «Diario estival de un hombre en pijama» a El País Semanal 
durante el verano de 2013, donde continuaría apareciendo hasta septiembre del año siguiente, colaboraciones recogidas todas ellas en Andanzas de un hombre en pijama (Roca 2011 y 2014). Los trabajos que componen Memorias de un hombre en pijama se centraban en la observación de la vida cotidiana por un treintañero urbano, cuya atención se focalizaba en la reflexión sobre la vida afectiva y sexual de los hombres de su edad. En ellas nos interesan menos sus temas, que propendían a lo anecdótico — en algunos casos con cierta reificación sexista de las diferencias entre hombres y mujeres-, que la maduración de ese lenguaje aprendido en Emotional World Tour, que pasaba de lo autobiográfico a lo ensayístico. En Memorias de un hombre en pijama Roca se constituye más como un observador reflexivo de la realidad que como un narrador de sí mismo. Roca recurre todavía con frecuencia a la matriz narrativa que podríamos llamar de la escuela Bruguera —anécdotas costumbristas resueltas en un gag final—, pero se observa una creciente atención hacia el lenguaje analítico, basado en la elaboración textual y visual de conceptos, antes que hacia el narrativo.

En 2012 Paco Roca daría un salto cualitativo importante tanto en su uso de la retórica ensayística como en la consideración de sus colaboraciones de opinión con la publicación de "Crónica de una crisis anunciada», "Otra más sobre la crisis», ambas aparecidas en El País Semanal, y «El toro», realizada para I/ Corriere della Sera (Paco Roca 2012: 229-237, 240-241 y 246-247). En ellas Roca se despojaba del pijama para autorrepresentarse dentro de sus cómics ya de manera inequívoca como una voz autorial que investiga y opina, usando su avatar biográfico para clarificar que se trata de un punto de vista, valioso entre otras razones por hacer uso del potencial expositivo del cómic para presentar ideas de un modo nuevo. Estas colaboraciones demuestran, en definitiva, que cuando esos periódicos encargan estos cómics sobre la crisis en España están interesados en lo mismo que buscarían en un ensayista literario, es decir, no sólo en su punto de vista sobre la realidad, sino también en su modo de contarlo.

Cuando el hombre en pijama regresó en 2013 a El País Semanal, lo haría ya definitivamente convertido en esa voz ensayística que había ido refinando en los años anteriores, con un total dominio de la trama de nueve viñetas con la que había empezado a trabajar en Emotional World Tour. Muchas de las tiras recogidas en Andanzas de un hombre en pijama se construyen presentando un hecho anecdótico que le sucede al hombre en pijama, pero que ahora se resuelve en reflexiones de mayor calado. Pero aparece además ahora un trabajo metarreflexivo sobre el 
propio trabajo creativo, ya sea sobre sus condicionantes materiales, como el problema de «El público infiel» en un mercado tan débil como el del cómic, ya sobre la experiencia misma de la creatividad en «La obligación de crear», «La depresión postparto» O «El punto final» (Roca 2014: 22-23, 34-35, 28-29 y 46-48). Junto a estos aparecerán denuncias de la clase política nacional como «El enigma de la clase política», críticas a la patente de semillas por empresas alimenticias en "Y las corporaciones crearon la vida», o reflexiones de corte existencial sobre la necesidad reescribir el propio pasado o sobre cómo valorar la propia vida en «La eterna reescritura» $\mathrm{y}$ «El balance final» (Roca 2014: 26-27, 60-61, 30-31 y 42-43).

La fuerza de este lenguaje ensayístico de Paco Roca ha llevado a los editores a seguir solicitando colaboraciones suyas, como las aparecidas en el número especial dedicado a celebrar los cuarenta años de El País Semanal. Significativamente, en esta ocasión se le solicitó traducir al lenguaje del cómic una serie de reportajes aparecidos en el suplemento dominical, en los que muestra el grado de depuración del lenguaje gráfico aplicado a la comunicación de ideas que ha alcanzado, utilizando indistintamente fragmentos narrativos, dibujos simbólicos, estructuras cerradas de nueve viñetas o usos diagramáticos de la página completa (Roca 2016).

Este uso de la retórica de la autobiografía aparece inscrito también en aquellos trabajos que se han interesado por un enfoque más próximo al reportaje que a la crónica, y que han proliferado gracias tanto al interés que hemos señalado en el cómic de temática social como a la aparición de nuevos fenómenos sociales como el 15-M. Yes We Camp! Trazos para una ( $r$ ) evolución es un volumen que recoge un conjunto heterogéneo de colaboraciones: hay ensayos de sociólogos y economistas como Vicenç Navarro y Àngels Martínez Castells o de escritores como Isaac Rosa, junto con una selección de diversos cómics, muchos de ellos aparecidos en red inmediatamente después del $15-\mathrm{M}$, que con frecuencia poseen un tono similar al de los trabajos que hemos visto hasta ahora. Resulta muy significativo en este sentido que uno de los gestos realizados en este volumen sea precisamente la recuperación de la tradición de cómic reflexivo político de la Transición, con la recuperación de «Tótem» y «Diccionario Básico Elemental», dos de las colaboraciones para El Papus de Carlos Giménez e Ivá, además de una de las crónicas del hombre en Pijama de Paco Roca, que por entonces sólo contaba con la edición regional de Las Provincias (Yes We Camp! 2011: 29-30 y 92-94). La mayoría de las colaboraciones trataban, sin embargo, de describir en un tono autobiográfico muy directo la 
simple experiencia del contacto con el movimiento del $15-\mathrm{M}$, con frecuencia dando un tono trascendental a la experiencia (Yes We Camp! 2011: 27-28 y 66-67). Pero aparecían también algunas colaboraciones que demostraban el impacto de los trabajos vistos de Gallardo y Roca, partiendo de la experiencia para realizar una reflexión, como las dos colaboraciones de Santiago García y Pepo Pérez «Spanish Revolution» y «Spanish Revolution \#2. Barcelona», entre las que se establecía además una clara relación dialéctica (Yes We Camp! 2011: 11-12 y 84-49). La primera de ellas se planteaba lo inimaginable de la violencia policial que parecía acechar a la toma de la plaza de Sol, contrastándola con los relatos de la memoria familiar de los últimos años, duros, del franquismo. El 15-M parecía surgir así casi como un desarrollo orgánico de esa evolución democrática sufrida por el país. Frente a las visiones trascendentes, el trabajo de García y Pérez no temía en mostrar un cierto grado de distancia inicial con lo que estaba sucediendo. «Spanish Revolution \#2. Barcelona» dialoga con el texto anterior, en primer lugar presentando la reacción de los autores a las críticas a las que fueron sometidos por el tono del trabajo anterior, hecho público en red de inmediato tras su creación, pero también modificando la interpretación de la situación a partir de la observación de los actos de violencia policial sucedidos en Barcelona el 27 de mayo de 2011. Utilizando imágenes de prensa, tweets, correos electrónicos, dibujos, imágenes de televisión, García y Pérez documentan sus reacciones a aquella carga policial, convirtiendo el hecho mismo de la documentación en el centro de su reflexión

También derivada de una respuesta personal al 15-M surgió la obra de Manel Fontdevila No os indignéis tanto (Fontdevila 2013), probablemente el ensayo en forma de cómic más interesante surgido como respuesta al movimiento. Fontdevila cuenta con una larga experiencia de trabajo en el humorismo político, colaborando desde los años ochenta en el diario de Manresa Regió7 (Fontdevila 2000), labor que ha continuado después en la prensa nacional, primero en Público y después en eldiairo.es (Fontdevila 2011, 2012a, 2012 b y 2014), lo que le ha convertido en alguien constantemente dedicado a la producción de opinión política a través del humor. Y fue precisamente en esas colaboraciones periodísticas, como ha estudiado Joaquim Noguero, donde Fontdevila fue desarrollando progresivamente un yo autoral representado, como en el caso de las autobiografías que hemos visto antes, por su autorretrato, que comenzó a introducir en sus colaboraciones para Regió7 a mediados de los 90. (Noguero 2010: 15). Noguero, que no duda en relacionar este recurso con la voz autoral de Montaigne, considera esta voz autoral

\footnotetext{
${ }^{6}$ El tono ensayístico dominará también en la colaboración de Pere Joan, "Tengo mis dudas, pero...», extenso texto de opinión en el que domina lo textual sobre lo visual, que con frecuencia repite lo que enuncia el texto, pero que no deja 
«una creació: va néixer com una instància narrativa, un invent que li servia per combinar la distància en la mirada-sobre-un-tema amb la complicitat-proximitat del lector», que convierte al dibujante en un periodista, pero, sobre todo, en un opinador (Noguero 2010: 15, 17 y 31). Fontdevila utilizará de forma regular esa presencia del autor a través de la caricatura en una serie desarrollada para este periódico, "M'agrada que em facim aquesta pregunta», en la que opina de manera monográfica sobre un tema que escoge, estructura sobre la que continuará trabajando durante años en la serie que creó junto a Albert Monteys para El Jueves, «Para ti, que eres joven», en la que sin abandonar el humor costumbrista que define a la revista se apuntaba, dentro del humor, una evolución a la reflexión sociocultural (Noguero 2010: 17).

Por otras vías diferentes a las de quienes partieron de la autobiografía, Fontdevila desarrolló una voz autoral dirigida a la opinión trabajando directamente en el medio periodístico, que colocará en el centro de No os indignéis tanto. La obra se abre con un explícito tono autobiográfico, iniciándose con un la lectura del libro de Stéphane Hessel Indignaos en un viaje en avión inmediatamente después del 15 de mayo de 2011, pero de inmediato pasa a centrarse no en su experiencia del evento sino en la reflexión sobre los elementos en juego en el mismo. El primer segmento de la obra analiza la situación política y los privilegios de los políticos en la estala de la crisis de 2008, volviendo sobre unos temas y una iconografía —obreros, banqueros, policías, la clase media, significativamente la única que aparece individualizada en su representación - con los que ha trabajado durante años en sus viñetas para Público. Como los trabajos de Paco Roca sobre la crisis realizados en 2012, este primer ensayo tiene un tono divulgativo, aunque constituye una clara lectura política de la situación posterior a la crisis por parte de Fontdevila.

Es en el tercer segmento de la obra "Gorila y cia.», donde Fontdevila elabora un ensayo de verdadera originalidad, vinculado a la crítica a los medios que articula la mayor parte del libro. En estas páginas, Fontdevila reflexiona sobre el papel del humor en la definición de lo que es tolerable en el discurso público, argumentando que los cambios en el nivel del humor conllevan cambios en la tolerancia a ciertas formas de discurso público que derivan, inevitablemente, en una ampliación de la libertad de expresión. El tono metarreflexivo que domina en todo No os indignéis tanto lleva a Fontdevila a cerrar la obra con una sutil ironía, tras haber hablado de la importancia del humor para modificar los marcos de la libertad de expresión, que son en 
realidad los de la democracia, trayendo una breve reflexión sobre cómo el humor a través los medios digitales y las redes sociales puede convertirse en un desactivador político también. Fontdevila demuestra así una vivacidad en su pensamiento que le lleva no sólo a cuestionar la realidad que observa, sino en ocasiones también a no estar de acuerdo consigo mismo.

El trabajo de Fontdevila muestra una evolución completamente diferente a la de Paco Roca hacia la integración de sí mismo en el cómic para construir una voz autoral desde la que ofrecer sus reflexiones sobre la realidad, que en su caso se desarrolla dentro del cómic de humor y el trabajo directo en la prensa, pero que ofrece como resultado un modo de abordar el ensayo en forma de cómic capaz, sin abandonar el humor, de elaborar una reflexión profunda no sólo sobre la realidad nacional, sino sobre el propio medio del que se vale para pensarla.

No podemos olvidar que, junto a la historia y la autobiografía, las formas documentales y el reportaje han sido la línea de no ficción que ha tenido una mayor importancia en el desarrollo de líneas de reflexión ensayística en el cómic contemporáneo, presencia que también se ha dejado sentir en la producción española (Chute 2016). Como en los trabajos que hemos visto hasta ahora, predominan en el reportaje los temas marcadamente sociales, de los cuales es un buen ejemplo el volumen Viñetas de vida (2014), que reúne una serie de reportajes sobre proyectos para la cooperación al desarrollo encargados por Oxfam Intermón a diversos autores de cómic. En ellos encontramos muchas de las características que vimos en los cómics autobiográficos, desde el uso de estructuras de página regulares al enfoque entre el cuaderno de viaje y el ensayo, lo que muestra el constante entrecruzado de recursos y elementos retóricos entre los distintos enfoques que son parte de este giro común hacia la no ficción en el cómic de las últimas décadas.

En las páginas de Viñetas de vida podemos encontrar reportajes puros, como el excelente «Femmes des fraises», denominado explícitamente reportaje por sus autores, Isabel Cebrián y Álvaro Ortiz, que escogen permanecer totalmente ausentes de sus páginas para tratar de presentar simplemente lo que sus palabras y dibujos captaron (Viñetas de vida 2014: 20-32). Un tono muy diferente tiene la colaboración de Miguel Gallardo, «Aquí vive dios», que utiliza una estructura dialéctica para presentar lo que creía saber sobre la República Dominicana y la cooperación al desarrollo, para inmediatamente contrastarlo con lo que aprendió después en su visita al país (Viñetas de vida 2014: 50-57). Parte de un par de premisas de verdad, las desmonta 
y llega a una conclusión general sobre la relación entre poder y ciudadanía. Gallardo no trata, por tanto, de representar la experiencia, lo observado, sino que trata de pensar las condiciones que hacen posible la situación de desigualdad observada y la necesidad de la colaboración, para concluir con una interpretación general que trata de ser una llamada a la empatía del lector, cuya distancia con el objeto de su ensayo ha tratado de borrar.

Como Gallardo, Paco Roca es el otro autor que se encuentra más cerca del ensayo en «Mauritania: un país sin conductor», en el que muestra una vez más la riqueza de sus recursos expresivos utilizando diversos estilos plásticos y formas de composición para cada nivel (Viñetas de vida 2014: 76-87). Roca inicia su trabajo como un reportaje, reafirmando la retórica de la observación directa propia del género utilizando para ello apuntes en blanco y negro de su propio cuaderno de viaje. Pero pronto suma a esta observación directa la investigación, que presenta a través de viñetas perfectamente definidas o páginas diagramáticas, siempre a color, en las que la relación entre el texto y la imagen no es puramente representativa, como sucedía en el nivel del reportaje, sino argumentativa, interpretando los dibujos aquellos datos que el texto nos va ofreciendo.

Inevitablemente, Viñetas de vida muestra que son aquellos autores que más han practicado el cómic ensayístico — Gallardo y Roca— los que mejor dominan su lenguaje, lo que les lleva en distintos momentos y de diferentes formas a alejarse de la ortodoxia del lenguaje del reportaje. Pero el reportaje en forma de cómic más formalista ha demostrado también en los últimos años que es capaz de convertirse en un vehículo de ideas, como demuestra la obra de Jorge Carrión y Sagar Barcelona. Los vagabundos de la chatarra (2015), planteado como una pesquisa sobre la vida alrededor de la chatarra que se produce, y con la que se comercia, en la ciudad. Carrión y Sagar siguen el modelo de referencia para el cómic de reportaje, la obra de Joe Sacco - a quien en un giro metarreflexivo entrevistan en las últimas páginas del libro (Carrión y Sagar 2015: 97-101)—, en el que la presencia del autor dentro de las páginas trata de mostrar no tanto un punto de vista sobre lo observado como afirmar que todo lo que se narra es el fruto de la observación directa. Si el uso de la presencia de los autores es diferente al de los cómics que parten de la retórica autobiográfica, no menos diferente es la puesta en página, que en su búsqueda de realismo documental debe permanecer focalizada en todo momento no sólo sobre lo que se observa sino, sobre todo, sobre quien está hablando con los periodistas, sobre aquellos 
que nos van contando sus historias. El dinamismo del dibujo de Sagar y su gusto tanto por el detalle como por el gran panorama son capaces de sostener este intento de captación naturalista de la realidad barcelonesa.

Pese a toda esta retórica documental, Barcelona. Los vagabundos de la chatarra, va mucho más allá de ser una simple captación de la realidad. La selección del objeto a observar parte de una idea compleja de la basura como paradójico indicador de un rango de civilización, que merece nuestra atención en un momento en que esa misma civilización entra en crisis, atrapando en una economía de la subsistencia miserable a los inmigrantes que han Ilegado a Europa en busca de esa civilización material que colapsa a cámara lenta. Explorando esta subeconomía de la chatarra, Carrión y Sagar tratan de acabar con la invisibilidad en el discurso social de quienes, con la crisis, son cada más visibles en las calles de Barcelona. Por ello, Barcelona. Los vagabundos de la chatarra se convierte en una reflexión sobre la construcción de la atención colectiva sobre ciertos aspectos de la realidad a base de ignorar otros, que Carrión y Sagar convierten en una sutil crítica al modelo de sociedad nacional que se está construyendo en Cataluña.

El cómic se abre con una doble página de la manifestación «Catalunya, nou estat d'Europa», celebrada el 11 de septiembre de 2012 durante la Diada (Carrión y Sagar 2015: 6-7). Entre quienes se concentran frente a un simbólico Arco del Triunfo que ocupa el centro de la ilustración, Carrión y Sagar colocan a un casi invisible recolector de chatarra. El contraste entre el discurso social y la realidad de la sociedad no podría ser más claro, convirtiendo la obra no sólo en un reportaje, sino en una reflexión crítica contra la focalización exclusiva de una sociedad nacional en problemas políticos que dejan de lado ciertas realidades sociales, exacerbadas por la crisis. La obra se cierra de forma simétrica, con una nueva página doble que nos sitúa un año después de la anterior en el antiguo mercado de Encants Vells, ahora transformado en una gran arquitectura que, en palabras de su arquitecto, reafirma la marca Barcelona, declaración que es traída irónicamente para criticar el triunfalismo cultural de ciertas formas de desarrollo urbanístico que Barcelona lleva décadas sufriendo (Carrión y Sagar 2015: 94-95).

El carácter documental plenamente logrado de Barcelona. Los vagabundos de la chatarra no impide que un uso inteligente de la disposición estructural de las escenas que fueron captadas según los protocolos propios del reportaje permita colocar frente al lector una serie de 
ideas complejas, ampliando los modos de abordar el ensayo en el cómic en el proceso.

\section{Narración y ensayo: relatos históricos y relatos de ficción}

Autobiografías, cuadernos de viajes, reportajes, todos ellos son géneros de no ficción que se han aclimatado al medio del cómic en las últimas décadas, ofreciendo espacios para la apertura del cómic hacia el ensayo. Pero también dentro de las formas más narrativas encontramos en el cómic reciente una propensión hacia el ensayo que no podemos pasar por alto.

Si la narración histórica fue una de las primeras formas de no ficción en aparecer y proliferar en el cómic, lo cierto es que su evolución hacia el simple relato de aventuras en distintas tradiciones nacionales primero y después, a partir de la publicación de Maus (1991) de Art Spiegelman, hacia la memoria histórica, ha reducido el género a sus principios narrativos puros, sin permitir que entrasen en él esos elementos ensayísticos que vengo persiguiendo. Sin embargo, en los últimos años ha aparecido también un nuevo tipo de cómic histórico que, si bien se aleja de las convenciones formales que hemos visto en autobiografías y reportajes —la presencia del narrador integrado en el espacio diegético, etc.—, que por razones obvias serían inasumibles por un cómic histórico, ha tratado de adentrarse en grandes construcciones históricas que poseen una clara intención reflexiva sobre su objeto.

La obra ganadora del Premio Nacional de Cómic de 2015, Las Meninas, de Santiago García y Javier Olivares es un ejemplo muy claro de ello. Con una compleja estructura, que partiendo del recuento de las pinturas de la corte tras el funeral del rey Felipe IV en 1665 se extiende a lo largo del tiempo y el espacio, Las Meninas no sólo utiliza para su relato el cuadro que le da título, ni únicamente la vida de quien lo pintó, sino también las palabras y experiencias de quienes pensaron en distintos momentos a lo largo de los siglos posteriores la obra de Velázquez. El relato se estructura en tres extensos segmentos, cuya interpretación conjunta permite acceder al significado profundo que García y Olivares han dado a su exploración de la historia y la cultura alrededor del cuadro de Velázquez. El primer segmento se titula «La Ilave», referencia al trabajo de Velázquez en la corte como aposentador del rey. En el momento en que se comienza una investigación para ofrecer a Velázquez la Cruz de Santiago, este se considera, a sus cincuenta y siete años, como un pintor sin obra maestra, pero que ha hecho de la pintura no un oficio, sino un arte (García y Olivares 2015: 17). Velázquez aparece a través de las entrevistas 
del investigador de la orden de Santiago como un pintor que nunca tuvo taller ni vivió de la venta de su obra, sino que la realizó mientras trabajaba para el rey, a quien había conocido en 1623, y que había hecho de inmediato posible la dedicación casi exclusiva de Velázquez a su pintura (García y Olivares 2015: 34-35).

La segunda parte, «El espejo», se abre con un Picasso niño que visita con su padre el museo del Prado, interesado no por la pintura, sino por el genio, que indudablemente Velázquez es (García y Olviares 2015: 38). Velázquez continúa siendo presentado a través de entrevistas y recuerdos como un pintor que se distingue de los demás, por así decirlo, en su desmaterialización. Cuando participa en una justa poética poco después de llegar a Madrid, Velázquez la ganará no pintando, sino por encima de todo pensando antes de comenzar a pintar (García y Olivares 2015: 46-47). Al mismo tiempo Velázquez no se muestra nunca interesado en buscar trabajo como pintor, sino en desarrollar su arte, frente a aquellos que, como Rubens, defienden una concepción industrial del arte (García y Olivares 2015: 58). Por ello «Las Meninas» no será un retrato, sino una obra de arte realizada sin encargo alguno, sin otra función que representar la maestría pictórica de Velázquez. El relato de Juan de Pareja, esclavo liberado por orden del rey y convertido en pintor, insiste en el valor que el arte confiere a quien lo practica, contrastando la idea del valor artístico dominante en la época de Velázquez y la que él comienza a encarnar.

Es en «La cruz», el último capítulo de Las Meninas, donde la reflexión de sus autores adquiere mayor transparencia. Si la llave le abrió la corte y el espejo fue la forma que tomó el arte que pudo desarrollar bajo la protección del rey, la cruz será la recompensa inevitable, pese a la resistencia de la propia orden, cuyos valores no son capaces de reconocer el valor de Velázquez (García y Olivares 2015: 157-159). La obra se cierra con la imagen de Velázquez frente al cuadro y a su espalda, la imagen de todos aquellos que han continuado mirando el cuadro, de Dalí y Picasso al Equipo Crónica, pasando por Michel Foucault y Antonio Buero Vallejo. Y, por qué no, también Santiago García y Javier Olivares.

Las Meninas nos coloca a lo largo de sus páginas no ante la historia del retrato real que nunca fue, sino ante todo lo que ha estado activo en la mente de quienes la han contemplado a lo largo del tiempo: la idea del genio, el valor trascendente del arte. Pese a su carácter histórico, la obra de García y Olivares no está construida siguiendo una estructura narrativa lineal, el cauce de una vida, la historia de un cuadro, sino que se sostiene sobre una estructura argumentativa, en 
la que cada capítulo es un paso en un argumento hacia una comprensión concreta de la figura y la obra de Diego de Velázquez, pensado como un creador que, contra la lógica de todos los valores de su tiempo, hizo de su pintura un arte en el sentido moderno.

El mismo tipo de estrategia discursiva, basada en el montaje de secuencias narrativas breves, que nos permite acceder al sentido de Las Meninas, está presente también en la otra gran obra de temática histórica aparecida en los últimos años: La casa. Crónica de una conquista, de Daniel Torres (2016), Torres, una de las figuras fundamentales del cómic español de los años ochenta, dedicado durante décadas al relato de ciencia ficción, ofrece en La casa el intento más ambicioso y explícito de realizar un ensayo histórico, que convierte el espacio que habitamos en el lugar privilegiado para observar la humanidad (Torres 2016: 7). Torres presenta la obra como «una colección de relatos extraídos de ese pozo del pasado» (Torres 2016: 6), pero la compleja variedad estilística que presenta lleva La casa más allá de la mera colección de relatos históricos. Cada secuencia reúne, junto a las breves secuencias narrativas, diagramas y datos históricos que dan por momentos al libro un tono demasiado cercano al didactismo que en el pasado tuvo el cómic histórico. El montaje sucesivo de estos diversos niveles y la interpretación conjunta de cada segmento histórico nos van mostrando a través de la vida del hogar cómo el hombre asume desarrollos culturales con efectos diversos sobre su vida: desde el inicio de la agricultura hasta la entrada del espacio urbano en el mercado o los cambios en las prácticas de guerra, pasando por el inicio de la salubridad urbana. La casa en la historia acaba convirtiéndose en la excusa para hablar del desarrollo de un aspecto de la civilización humano, observado siempre desde el punto de vista del hogar, lo que da a La casa su tono de ensayo de historia de la civilización.

Daniel Torres es un caso casi único en el cómic español, en el que a diferencia de lo que ha sucedido en el mundo anglosajón, la generación de autores que comenzó su obra en los años setenta no se ha inclinado por el reportaje o el ensayo puro en sus cómics más recientes. Pero del mismo modo que, como hemos visto, el cómic histórico reciente, incluso en sus formas más narrativas, se ha inclinado hacia el ensayo, la obra de ficción reciente de algunos autores clásicos del cómic contemporáneo español muestra un interés por la reflexión que nos obliga, para concluir, a considerarla.

Tanto Carlos Giménez como Max, nombre con el que firma Francesc Capdevila, son dos narradores natos, interesados desde los comienzos de sus carreras en temas sociales y, en el 
caso de Max, también filosóficos. Sus obras, definidas desde los años setenta por series o ciclos narrativos centrados en un personaje recurrente, toman desde hace años la forma de relatos monográficos extensos, que demuestran su fidelidad hacia el cómic narrativo. Esto no impide que en trabajos recientes como Vapor (Max 2012) y Crisálida (Giménez 2016) pueda observarse una construcción articulada, antes que en el desarrollo de una trama, en una serie de escenas narrativas que funcionan como partes de una reflexión alrededor de un núcleo conceptual. Ambas obras, trabajos maduros no sólo estilísticamente, sino también en lo ideológico, con un cierto grado de desencanto en el caso de Carlos Giménez y de ironía vitalista en Max, pueden ser pensadas por todo ello como relatos-ensayo.

La obra de Max ha poseído siempre una vinculación estrecha con el mundo del pensamiento, ya fuese a través de sus propios relatos, como sucedía con el ideario contracultural más comprometido en los álbumes protagonizados por su personaje Gustavo, creado en 1977, o en trabajos directamente dirigidos a la difusión de ideas. Ya en 1978 Max publicó, junto a Paco Mir, otro dibujante particularmente propenso a lo intelectual, El Capital (Max y Mir 1978), una adaptación divulgativa que se valía de ilustraciones y cómics para hacer llegar a los lectores de manera didáctica los conceptos fundamentales de la obra de Karl Marx. Esa tendencia se ha acentuado con el paso de los años en sus obras narrativas, cada vez más inclinadas a la abstracción simbólica, además de continuar en ciertos trabajos concretos, como sus ilustraciones para la serie «Filosofía para profanos», serie de 10 volúmenes publicada desde 2001, en la que los textos de Maite Larrauri, dedicados a explorar un concepto en la obra de un filósofo, van acompañados de cómics realizados por Max en los que ofrece su propia interpretación.

Como apuntaba, es en Vapor (Max 2012), su relato más extenso hasta la fecha, donde Max ha llevado más lejos su interés filosófico. Vapor narra la vida en retiro de Nicodemo, un autodenominado anacoreta en busca de una experiencia trascedente que le permita poner fin a las tensiones que sobre el deseo impone el mundo moderno. A través de una parábola localizada en un desierto, paradójicamente habitado por diversos personajes que aparecen como metáforas de los estados emocionales de Nicodemo, Max reflexiona sobre la dificultad para alcanzar la mesura y la paz frente al mundo. Estructurando la obra a través de episodios simbólicos, encuentros sucesivos con distintos personajes que Nicodemo cree fruto de su imaginación, Max nos muestra al personaje sometido siempre en última instancia a las necesidades de su 
cuerpo. La elaboración visual de la obra demuestra un dominio total del medio en términos de caligrafía —estilo—y gramática —composición de página—, que no sólo atrapan al lector, sino que gestionan su atención dotando a ciertas secuencias de un alto valor simbólico, como el momento en que un entramado barroco viene a representar la creciente confusión de Nicodemo (Max 2012: 29), o como el sueño a través del cual el protagonista asiste a su propio conflicto interno, representado en la lucha entre su sombra perdida y un humanoide de nieve, que concluye con la destrucción de ambos (Max 2012: 53-58). Todo ello sin dejar de lado un dibujo altamente estilizado, que mira a la tradición infantil de los funny animals y a la exageración de los rasgos físicos que comparte tanto con la tradición del cómic humorístico e infantil como con el underground. Será precisamente esta densa estilización la que ofrezca un potencial comunicativo a sus representaciones, que no son en realidad tales, sino verdaderas construcciones, abstracciones, alegorías, metáforas. Incluso en la construcción textual del relato, Max recurre de manera constante a una tradición de relatos alegóricos y filosóficos, que va de la Biblia a las fábulas infantiles e incluso a la narración filosófica de Friedrich Nietzsche, unidos a la expresividad sintética pero altamente evocadora de ciertos cómics de principios de siglo, como The Wiggle Much, explícitamente citado al comienzo de la obra (Max 2012: 2 y 90), o el Krazy Kat de George Herriman, abriendo vías completamente nuevas para el contacto entre el cómic y el ensayo.

Esta unión entre narración, con frecuencia parabólica, y reflexión es una constante en el Max maduro. Incluso en "Trampantojos», sus breves reflexiones publicadas semanalmente desde 2014 en el suplemento literario de El País, Babelia, Max recurre a micronarraciones para hacernos llegar sus puntos de vista, practicando una forma de crítica cultural irónica que se vale con frecuencia de figuras y referencias literarias. En gran medida muestra en estas colaboraciones el reverso de las de Paco Roca, de la opinión sobre el mundo, para centrarse en breves reflexiones culturales. Incluso en su colaboración para la recopilación de ensayos Supercómic. Mutaciones de la novela gráfica contemporánea (García 2013: 137-161), titulada «M + M» y en la que colabora con Mireía Pérez, pese a tratarse de un ensayo sobre el cómic como medio y sus posibilidades creativas, escoge una narración simbólica para ello.

Muy diferente al trabajo de Max es Crisálida, de Carlos Giménez (Giménez 2016), realizada sin romper con las características que han definido toda su obra —-ficción autobiográfica 
con base en la experiencia personal del mundo, narrada a través de un estilo cuyo expresionismo emotivo trata de ir al núcleo sentimental de su relato-, pero para acercarse esta vez casi exclusivamente a la ilustración de un concepto, esa crisálida que da título a la obra. Giménez aborda aquí no un relato, sino esencialmente una idea, que la muerte no es un estado, sino un proceso inscrito en nuestro envejecimiento biológico y social (Giménez 2016: 9).

A lo largo de Crisálida los intercambios entre los dos personajes protagonistas, el tío Pablo y Raúl, y entre el tío Pablo y los amigos que lo escuchan en silencio (Giménez, 2016: 11), se unen a un diario de Raúl, «Cuaderno de bitácora», sobre la experiencia de morirse despacio, para crear, pese a la construcción en apariencia realista, una dirección discursiva constante en la que lo biográfico se convierte en una mera vía para la reflexión. El cómic posee momentos indisimuladamente biográficos, como las páginas dedicadas a los distintos intentos de llevar al cine Muñecos, la obra que dentro de Crisálida remite a su clásico Paracuellos (Giménez 2016: 26-31). Pero es mucho más importante el uso de diversas máscaras para ocultar la autobiografía directa, que acaba por convertir la obra también en una reflexión sobre la acumulación de máscaras en la ficción autobiográfica y el valor sacrificial de las mismas. Giménez utiliza como personajes esencialmente intercambiables a su personaje clásico el tío Pablo y a Raul, que no es sino otro posible Carlos Giménez, que tras contemplar las fotos de toda una vida y sintiéndose irremediablemente preso en la crisálida, decide suicidarse (Giménez 2016: 63-66). Giménez, después de haber sacrificado a su máscara, todavía jugará más con la idea de las identidades interpuestas en un epílogo en el que el tío Pablo habla de una creación de Raúl llamada el abuelo Paquito, otro sosias, otra vuelta de tuerca, probablemente otro Carlos Giménez posible.

Como es habitual en los cómics de Giménez, lo personal se une a lo social, en este caso a través de una de las peroratas de sus personajes sobre el presente como una buena época para morirse, por estar sometida a un constante cambio desestabilizador y a unas perspectivas de futuro que es difícil imaginar mas que en términos negativos (Giménez 2016: 33-35), con especial atención a la creciente vinculación entre la religión y la violencia, que al estallar en el atentado contra Charlie Hebdo marcó a los personajes (Giménez 2016: 41-42).

La superposición de estos niveles — la centralidad de la idea de crisálida, el juego de las máscaras ficticias y lo biográfico, el comentario social- contribuyen en conjunto a dar al volumen una unidad expresiva e ideológica que hace el relato, lo que sucede en Crisálida, 
menos importante que lo que éste vehicula. No nos encontramos aquí con el uso de los recursos narrativos de la autobiografía que veíamos en Gallardo o Roca, sino con la depuración, como decía al principio, de un modo de contar las cosas que durante décadas Carlos Giménez ha pulido para hacerlo suyo, al servicio ahora de una idea, para constituir así un verdadero ensayo sobre saberse al final de la vida.

\section{Conclusión: los autores de cómic en la esfera pública}

Todas las obras que hemos visto hasta aquí creo que constituyen intentos valiosos de realizar en el cómic funciones equivalente a las del ensayo, valiéndose para ello de las posibilidades de su propio lenguaje visual, al mismo tiempo que tratan —en casi todos los casos— de alejarse de las vías más establecidas —estilísticamente, pero también en el mercado— de abordar la no ficción en el cómic.

En muchos casos, el interés por abordar cuestiones sociales de manera crítica ha dado a estos cómics una relevancia social notable, que está contribuyendo a dar al cómic una posición de valor dentro del consumo cultural de los adultos como no la había tenido desde los años setenta. Poco a poco, de manera todavía incompleta, la recepción de estas obras está contribuyendo a dar a los creadores de cómic el lugar que como intelectuales públicos les corresponde. El reconocimiento que algunos medios de comunicación ofrece a ciertos creadores, abriendo para ellos las páginas de sus publicaciones, es sin duda parte de este proceso, como lo es también la inclusión de algunas de estas obras en programas académicos o la participación en ciertos foros públicos especializados, como ha sucedido en los casos de Gallardo y Paco Roca.

El reconocimiento que como productores culturales ya reciben los creadores de cómics, al mismo nivel que los que practican otras artes, todavía no tiene un equivalente en el reconocimiento del carácter específico de su práctica intelectual, de las posibilidades del lenguaje con el que trabajan para ofrecer intervenciones significativas en debates públicos. Con este trabajo he querido apuntar en esa dirección, estableciendo unas primeras referencias que nos permitan empezar a acercarnos al cómic como un medio posible más para el desarrollo del ensayo, de la reflexión sobre nosotros mismos y sobre la realidad en que vivimos. 


\section{Bibliografía}

ALTARES, Guillermo: «Novela gráfica, el cómic 'respetable'», El País (30 de enero de 2009). Consultado en http://elpais.com/diario/2009/01/30/cultura/1233270001_850215.html el 15/6/2017.

ALTARRIBA, Antonio: «La historieta española de 1960 a 2000», en Viviane Alary (ed.), Historietas, Comics y Tebeos españoles. Toulousse: Presses Universitaires du Mirail, 2002, pp. 76121.

ARROYO, Francisco M. y Adolfo USERO: Dossiers. Madrid: Ediciones de la Torre, 1980.

AZPITARTE, Koldo «El pijama no hace al hombre», en Paco Roca. Dibujante Ambulante. Valencia: Diputació de València / Museo Valencià de la II·lustració y la Modernitat, 2012, pp. 200-206.

BEATY, Bart: Comics versus Art. Toronto / Buffalo / Londres: University of Toronto Press, 2012.

BEATY, Bart y y Benjamin WOO: The Greatest Comic Book of All Time. Nueva York: Palgrave McMillan, 2017.

CAMPBELL, Eddie: «Eddie Campbell's Graphic Novel Manifesto», 2004. Consultado en http:// donmacdonald.com/2010/11/eddie-campbells-graphic-novel-manifesto/ el 15/6/2017 .

CARRIÓN, Joge y SAGAR, Barcelona. Los vagabundos de la chatarra . Barcelona: Norma Editorial, 2015.

CAU: «Editorial», CAU, 53 (febrero de 1979), p. 17.

CHANEY, Michael A. (ed.): Graphic Subjects. Critical Essays on Autobiography and Graphic Novels. Madison: The University of Wisconsin Press, 2011.

CHUTE, Hillary y Patrick JAGODA (eds.): «Comics \& Media», Critical Inquiry (Spring 2014).

CHUTE, Hillary L.: Disaster Drawn. Visual Witness, Comics, and the Documentary Form. Cambridge / Londres: The Belknat Press of Harvard University Press, 2016.

DÍAZ DE GUEREÑU, Juan Manuel: «El cómic español desde 1995», Arbor, 187 (septiembre de 2011), pp. 209-220.

DÍAZ DE GUEREÑU, Juan Manuel: Hacia un cómic de autor. A propósito de Arrugas y otras novelas gráficas. Bilbao: Universidad de Deusto, 2014.

DOPICO, Pablo: El cómic underground español, 1970-1980. Madrid: Cátedra, 2005. 
EL CUBRI: «Aventuras en el País de las Maravillas», Bang! Información y estudios sobre la historieta, 11, (1974), pp. 41-46.

EL CUBRI: El que parte y reparte se queda con la mejor parte. Madrid: Editorial Fundamentos, 1975.

EL CUBRI: «Una lección de biología del Dr. Römpp en 1936», Zona Abierta, 5 (otoño 1975), pp. $79,83,87,91,95,99,103,107$ y 111.

EL CUBRI: «Revolución científico-técnica versus lucha de clases», CAU, 46 (noviembrediciembre de 1977), pp. 36-47.

EL CUBRI: Sin título, CAU, 47 (enero-febrero de 1978), pp. 44-49.

EL CUBRI: Sin título, CAU, 49 (mayo-junio de 1978), pp. 18-29.

EL CUBRI: Tal como éramos. Alicante: Edicions de Ponent, 2008.

EL REFAIE, Elisabeth: Autobiographical Comics. Life Writing in Pictures. Jackson: University Press of Mississippi, 2012.

FONTDEVILA, Manel: Caràmbanus! 18 anys d'acudits a Regió7. Manresa: Angle Editorial, 2000.

FONTDEVILA, Manel: ¡La crisis está siendo un éxito!. Bilbao: Astiberri, 2011.

FONTDEVILA, Manel: ;Esto es importantísimo!. Bilbao: Astiberri, 2012.

FONTDEVILA, Manel: Profundamente anticlerical. Bilbao: Astiberri, 2012.

FONTDEVILA, Manel: No os indigneis tanto. Bilbao: Astiberri, 2013.

FONTDEVILA, Manel: En el lado bueno de la valla. Barcelona: Roca Editorial, 2014.

GALLARDO, Miguel: Toda la verdad sobre el informe «G». Alicante: Edicions de Ponent, 2000.

GALLARDO, Miguel: María y yo. Bilbao: Astiberri, 2007.

GALLARDO, Miguel y Paco ROCA: Emotional World Tour. Bilbao: Astiberri, 2009.

GALLARDO, Miguel: «Una navidad en casa», Panorama. La novela gráfica española hoy. Bilbao: Astiberri, 2013, pp. 177-179.

GARCÍA, Luis, Adolfo USERO, OMAR y Felipe HERNÁNDEZ CAVA: ARgelia. Vitoria: Ikusager Ediciones, 1981.

GARCÍA, Santiago: La novela gráfica. Bilbao: Astiberri, 2010.

GARCÍA, Santiago (coord.): Supercómic. Mutaciones de la novela gráfica contemporánea. Madrid: Errata Naturae, 2013.

GARCÍA, Santiago y Javier OLIVARES: Las Meninas. Bilbao: Astiberri, 2014. 
GIMÉNEZ, Carlos: Crisálida. Madrid: Reservoir Books, 2016.

GRAVETT, Paul: Graphic Novels. Everything You Need to Know. New York: Collins Design, 2005.

GUIRAL, Antoni: «1970-1995: un reloj atrasado y otro tren perdido», Arbor, 187 (septiembre de 2011), pp. 183-208

LLADÓ, Francisca: Los Comics de la Transición (El boom del cómic adulto 1974-1984). Barcelona: Glénat, 2001.

MAX y Paco MIR: El capital. Dibujos e historietas de Max y Mir sobre "El Capital», libro primero de K. Marx. Barcelona: Pastanaga, 1978.

MAX: Vapor. Barcelona: La Cúpula, 2012.

MAZUR, Dan y Alexander DANNER: Comics. A Global History, 1968 to the Present. Londres: Thames \& Hudson, 2014.

McCLOUD, Scott: Understanding Comics. The Invisible Art. Nueva York: HarperPerennial, 1994 (1993).

NOGUERO, Joaquim: «La crònica en viu», en Manel Fontdevila, retrat del cronista, Manresa: Ajuntament de Manresa / El Casino Centre Cultural / Museu Comarcal de Manresa, 2010, pp. 12-31s

Paco Roca. Dibujante Ambulante. Valencia: Diputació de València / Museo Valencià de la II.lustració y la Modernitat, 2012

PÉREZ DEL SOLAR, Pedro: Imágenes del desencanto: Nueva historieta española 1980-1986. Madrid: Iberoamericana-Vervuert, 2013.

ROCA, Paco: Arrugas. Bilbao: Astiberri, 2007.

ROCA, Paco: Memorias de un hombre en pijama. Bilbao: Astiberri, 2011.

ROCA, Paco: Andanzas de un hombre en pijama. Bilbao: Astiberri, 2014.

ROCA, Paco: «Una revista en viñetas. Paco Roca, premio Nacional de Cómic, reconstruye grandes crónicas publicadas en estas páginas», El País, 2.092 (30 de octubre de 2016), pp. 119-129.

SABIN, Roger: Adult Comics. An Introduction. Londres: Routledge, 1993.

RUIZ GIMÉNEZ, Eneko: «¿Lo llamo cómic, novela gráfica o tebeo? El eterno debate», El País (17 de marzo de 2017). Consultado en http://cultura.elpais.com/cultura/2017/03/15/ ka_boom/1489574683_699396.html el 15/6/ 2017. 
TORRES, Daniel: La casa. Crónica de una conquista. Barcelona: Norma Editorial, 2016.

VILCHES, Gerardo: «La primera etapa de El Jueves: un análisis de los primeros 26 números del semanario», Cuco. Cuadernos de cómic, 2 (abril de 2014), pp. 137-158.

Viñetas de vida. Bilbao: Astiberri, 2014.

WITEK, Joseph: Comic Books as History. The Narrative Art of Jack Jackson, Art Spiegelman, and Harvey Pekar. Jackson y Londres: University Pres of Mississippi, 1989.

Yes We Camp! Trazos para una (r)evolución. Madrid: Dibbuks, 2011. 